\title{
How Mechanical Ventilation Measurement, Cutoff and Duration Affect Rapid Shallow Breathing Index Accuracy: A Randomized Trial
}

\author{
Elaine Cristina Goncalves ${ }^{\mathrm{a}}$, Alessandra Fabiane Lago ${ }^{\mathrm{a}}$, Elaine Caetano Silva ${ }^{\mathrm{a}}$, \\ Marcelo Barros de Almeida ${ }^{\mathrm{b}}$, Anibal Basile-Filho ${ }^{\mathrm{c}}$, Ada Clarice Gastaldia, d
}

\begin{abstract}
Background: Decreased accuracy of the rapid shallow breathing index (RSBI) can stem from 1) the method used to obtain this index, 2) duration of mechanical ventilation (MV), and 3) the established cutoff point. The objective was to evaluate the values of RSBI determined by three different methods, using distinct MV times and cutoff points.
\end{abstract}

Methods: This prospective study included 40 subjects. Before extubation, three different methods were employed to measure RSBI: pressure support ventilator (PSV) ( $\mathrm{PSV}=5-8 \mathrm{~cm} \mathrm{H}_{2} \mathrm{O}$; positive endexpiratory pressure $\left.(\mathrm{PEEP})=5 \mathrm{~cm} \mathrm{H}_{2} \mathrm{O}\right)$ (RSBI_MIN), automatic tube compensation (ATC) $\left(\mathrm{PSV}=0, \mathrm{PEEP}=5 \mathrm{~cm} \mathrm{H} \mathrm{H}_{2} \mathrm{O}\right.$, and $100 \%$ tube compensation) (RSBI_ATC), and disconnected MV (RSBI_SP). The results were analyzed according to the MV period (less than or over $72 \mathrm{~h})$ and to the outcome of extubation $(<72 \mathrm{~h}$, successful and failed; $>72 \mathrm{~h}$ successful and failed). The accuracy of each method was determined at different cutoff points $(105,78$, and 50 cycles/ $\min / \mathrm{L})$.

Results: The RSBI_MIN, RSBI_ATC, and RSBI_SP values in the group $<72 \mathrm{~h}$ were $38 \pm 18,45 \pm 26$ and $55 \pm 22$; in the group $>72 \mathrm{~h}$, RSBI_SP value was higher than those of RSBI_ATC and RSBI_MIN $(78 \pm \overline{2} 9,51 \pm 19$ and $39 \pm 14)(\mathrm{P}<0.001)$. For patients with $\mathrm{MV}>72$ $\mathrm{h}$ who failed in removing MV, the RSBI SP was higher $(93 \pm 28,58$ \pm 18 and $41 \pm 10)(\mathrm{P}<0.000)$, with greater accuracy at cutoff of 78 .

Conclusion: RSBI_SP associated with cutoff point $<78$ cycles $/ \mathrm{min} / \mathrm{L}$

Manuscript accepted for publication December 29, 2016

a Department of Physiotherapy, Ribeirao Preto Medical School, University of Sao Paulo, SP, 14049-900, Ribeirao Preto, Brazil

bFaculty of Electrical Engineering, University of Uberlandia, Uberlandia, MG, Brazil

'Division of Intensive Care, Department of Surgery and Anatomy, Ribeirao Preto, Medical School, University of Sao Paulo, SP, 14049-900, Ribeirao Preto, Brazil

${ }^{\mathrm{d} C}$ Corresponding Author: Ada C. Gastaldi, Universidade de Sao Paulo - USP, Faculdade de Medicina de Ribeirao Preto (FMRP), Curso de Fisioterapia, Campus Universitario, Avenida dos Bandeirantes, 3900, Monte Alegre, CEP 14040-900, Ribeirao Preto, SP, Brazil. Email: ada@fmrp.usp.br

doi: https://doi.org/10.14740/jocmr2856w seems to be the best strategy to identify failed extubation in subjects with MV for over $72 \mathrm{~h}$.

Keywords: Ventilator weaning; Mechanical ventilation; Rapid shallow breathing index; Extubation; Physiotherapy; Automatic tube compensation

\section{Introduction}

Weaning from mechanical ventilation (WMV) consists in the transition from ventilator support to spontaneous breathing, which can occur abruptly or gradually [1-3]. Currently, 20$30 \%$ of the patients subjected to mechanical ventilation (MV) face difficulties during the MV withdrawal, which culminates in increased mortality and hospital costs $[4,5]$. In this context, weaning indices associated with the spontaneous breathing test (SBT) can help to identify patients that are able to breathe spontaneously $[6,7]$. Among these indices, the rapid shallow breathing index (RSBI) is the most often employed. One advantage of RSBI is that it is easy to measure, dismissing the need for sophisticated apparatus [8].

Originally, RSBI is evaluated after the patient had been disconnected from MV. Thus, the patient has to breathe spontaneously while connected to a respirometer for $1 \min$ [9]. The technological advances in mechanical ventilators and the increasing complexity of patients' conditions have led some authors to propose that RSBI should be measured with the individual connected to MV at minimum pressure support (PS) or continuous positive airway pressure (CPAP) [10-13], in an attempt to avoid respiratory distress upon disconnection.

A study performed with post-cardiac surgery patients, with an MV time of less than $12 \mathrm{~h}$, found no differences when comparing the two methods [14]. Moreover, some studies in patients who required MV for more than $72 \mathrm{~h}[15,16]$ have demonstrated that RSBI obtained with the use of PS was lower when compared to the traditional method described by Yang and Tobin [9].

Fabry et al [17] have introduced a new strategy known as automatic tube compensation (ATC). In this approach, named electronic extubation, the patient receives only the PS required to overcome the endotracheal tube resistance. This strategy benefits the patient by offering a reduced and more comfort- 


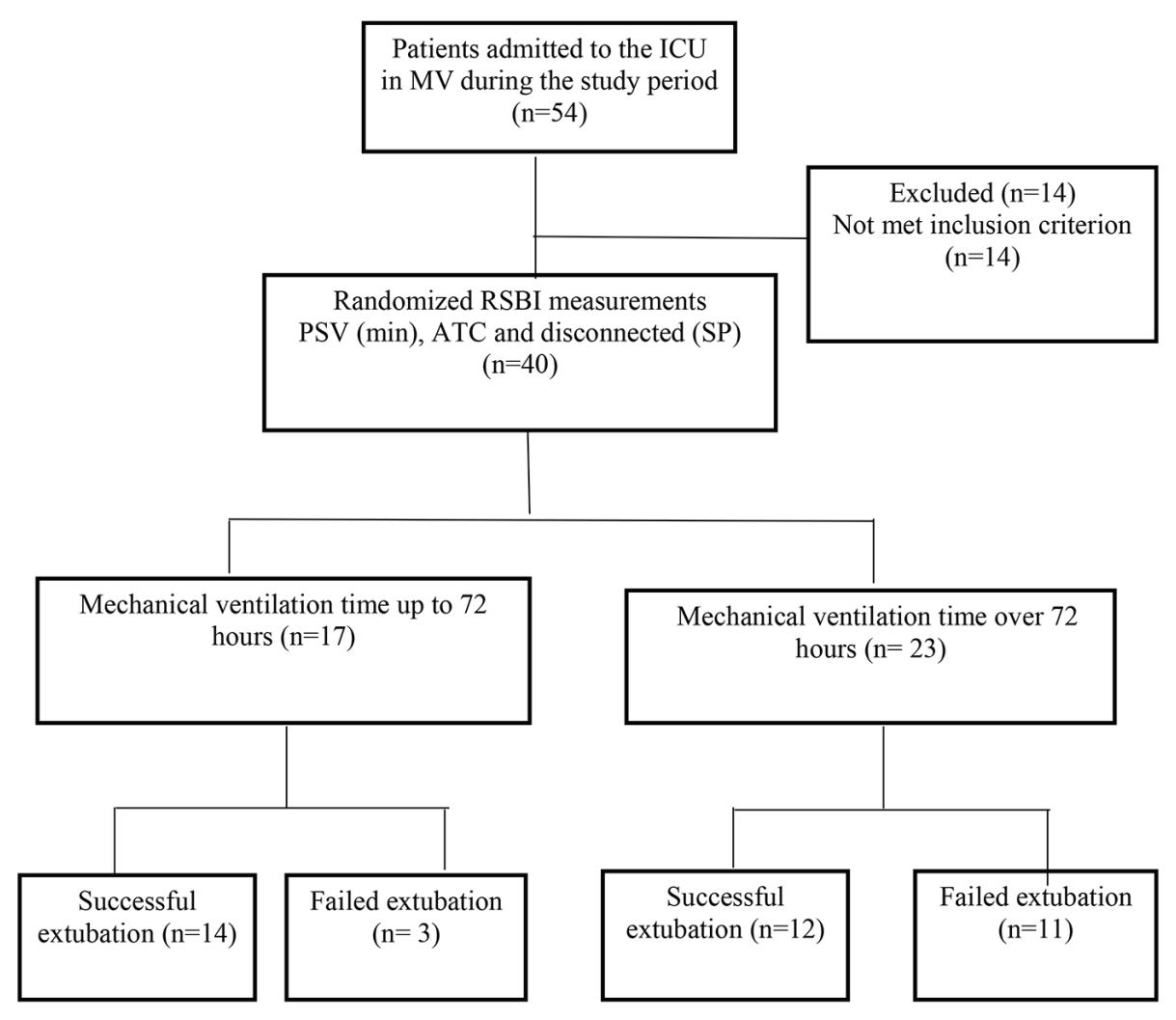

Figure 1. Flowchart of the study design.

able breathing pattern [18-21]. A few studies have suggested the use of ATC in the final stage of ventilator weaning [21, 22].

Yang and Tobin [9] established that values of RSBI lower than $105 \mathrm{cycles} / \mathrm{min} / \mathrm{L}$ predicted successful weaning and extubation. However, in this same study, it was shown that the accuracy of the index worsened in patients with major MV. Recent publications have demonstrated that not only that the method used to determine the index $[10,11]$ but also the established cutoff point might vary among different populations [23-25]. Investigations have shown that the average RSBI in patients that progress to successful ventilator weaning is 48 [25] and 50 [26] cycles/min/L. Verceles et al [27] tested the predictive value of RSBI in patients with prolonged $\mathrm{MV}$ and found that the group with successful ventilator weaning had an average RSBI of 78 cycles $/ \mathrm{min} / \mathrm{L}$.

In this context, we hypothesized that the method of obtaining the cutoff point and its value can influence the predictive value of RSBI in patients on MV specially the ones with more than $72 \mathrm{~h}$.

The current study aimed to compare the values of RSBI determined by the traditional method [9] to those achieved with PS or with ATC, using different days of MV and other proposed cutoff points.

\section{Materials and Methods}

This observational, non-interventional study was conducted at the general adult intensive care unit (ICU) of the University Hospital of the Ribeirao Preto Medical School, University of Sao Paulo, Ribeirao Preto, SP, Brazil, after the approval by the Institutional Research Ethics Committee under the protocol number 12741/2008, registered in the Brazilian records of clinical trials under number RBR-7nqxy5.

The participants' relatives received a detailed description of the study and signed a free and informed consent form that allowed and approved patient's participation.

\section{Subjects}

This study included all the subjects that 1) were admitted to the ICU during the study period, 2) were aged over 18 years, 3 ) were male or female, 4) used endotracheal tube, 5) received ventilator support via the ventilator Evita $\mathrm{XL}^{\mathrm{TM}}$ by Drager, 6) had successful WMV, 7) were tolerant of SBT, and 8) were ready for extubation.

WMV was initiated when the participant presented 1) resolution or improvement in the cause of respiratory failure, 2) suppressed sedation or neuromuscular blockade, 3) satisfactory level of consciousness (Glasgow $\geq 8$ ), 4) absence of fever $\left.\left(\mathrm{T} \leq 37.5^{\circ} \mathrm{C}\right), 5\right)$ presence of respiratory drive, 6) hemodynamic stability at minimal doses or in the absence of vasoactive drugs, 7) absence of decompensated coronary insufficiency or arrhythmia with hemodynamic repercussion, 8) arterial blood oxygen tension $\left(\mathrm{PaO}_{2}\right) \geq 60 \mathrm{~mm} \mathrm{Hg}$ with fraction of inspired 
Table 1. Demographic Data for the 40 Patients Included in the Study, Grouped According to Duration of the Mechanical Ventilation

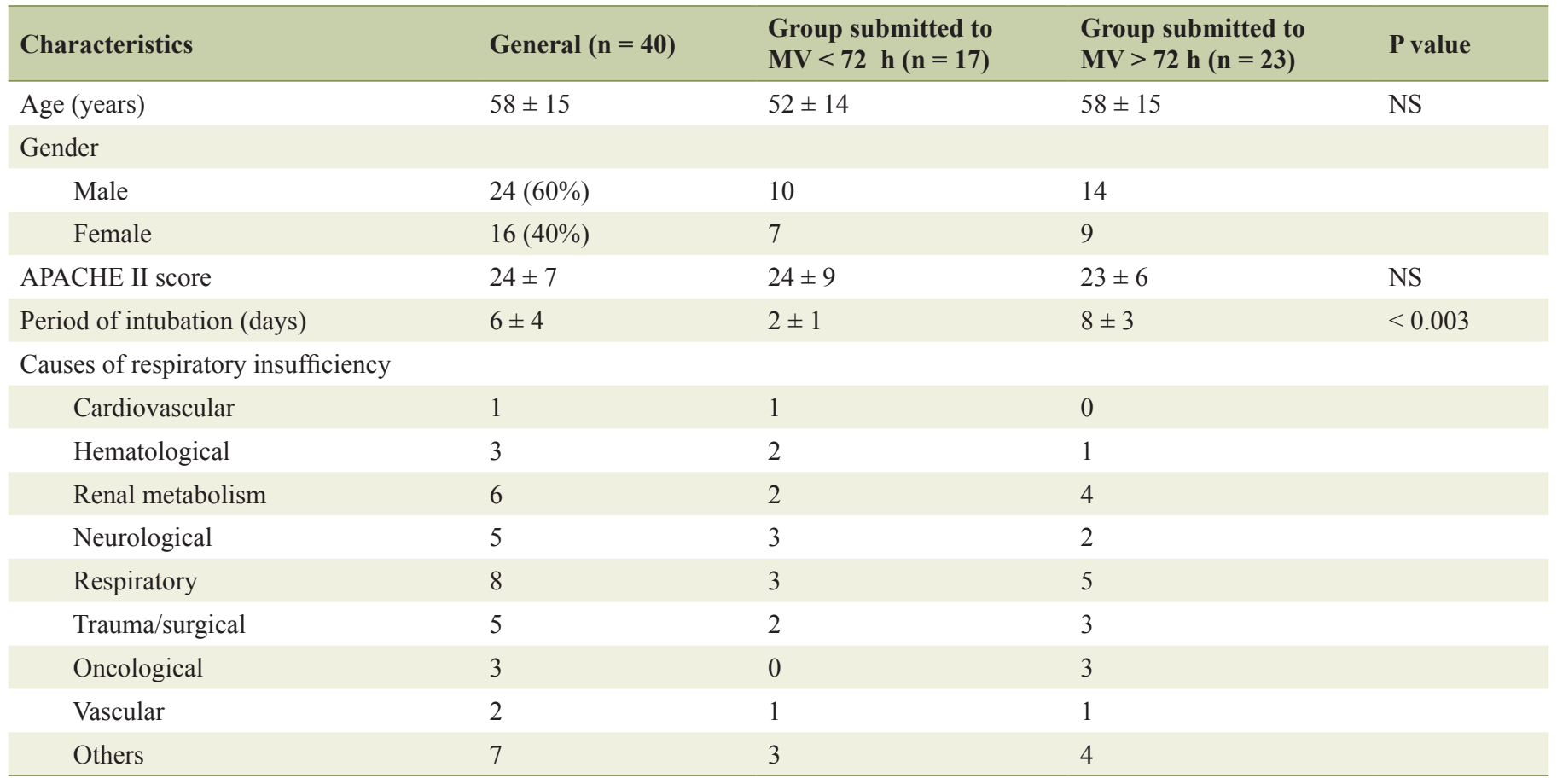

MV: mechanical ventilation; APACHE II: Acute physiology age chronic health evaluation; NS: without statistical significance. Values expressed as the mean and standard deviation.

oxygen $\left(\mathrm{FIO}_{2}\right) \leq 0.4$ and positive end-expiratory pressure $(\mathrm{PEEP}) \leq 5-8 \mathrm{~cm} \mathrm{H}_{2} \mathrm{O}[28]$.

Subjects with a history of tracheal or laryngotracheal disease, tracheostomy, accidental extubation, or chronic obstructive pulmonary disease were excluded from the study.

\section{Study protocol}

After the weaning was initiated, the ventilator parameters were reduced according to the patient's comfort and tolerance, until

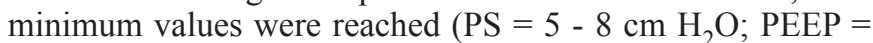
$5 \mathrm{~cm} \mathrm{H}_{2} \mathrm{O}$ ). The SBT was performed with a T-tube circuit in a semi-seated position during $30 \mathrm{~min}$ and the subjects were considered SBT tolerant and eligible for extubation in the presence of adequate tidal volumes $(6-8 \mathrm{~mL} / \mathrm{kg} /$ weight $)$ and in the absence of the following signs of intolerance to disconnection of MV: heart rate $>140 / \mathrm{min}$ or increased by $\geq 20 / \mathrm{min}$, systolic blood pressure (SBP) $180 \mathrm{~mm} \mathrm{Hg}$ or $90 \mathrm{~mm} \mathrm{Hg}$, respiratory rate $(\mathrm{RR})>35 / \mathrm{min}$, oxygen saturation by pulse oximeter $<$ $90 \%$ and symptoms such as agitation, anxiety, sweating, and altered level of consciousness [28].

Prior to extubation, RSBI was obtained via three different methods: RSBI_MIN, RSBI_ATC and RSBI_SP. The order of obtaining the index was randomly assigned using opaque, sealed envelopes containing each method, and the order was drawn at the time of data collection sequentially, which were opened by the physiotherapist at the moment of interventions.

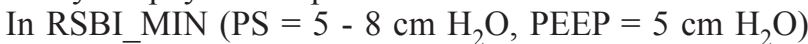

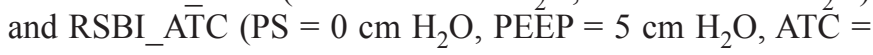

$100 \%$ ), those patients remained in these parameters during 60 $\mathrm{s}$ and after the RR and VE values were registered by the fan display. In RSBI_MIN, the automatic compensation mode of the tube remaine $\bar{d}$ off.

In RSBI_SP, the patient was disconnected from MV and connected to a calibrated respirometer for 60 s. VE was obtained from the respirometer monitor; RR was measured by counting the patient's thoracic cage movement for $1 \mathrm{~min}$.

For all the RSBI methods, the VT (L) was calculated as $\mathrm{VE}$ (L/min) divided by respiratory frequency (RR, breaths/ min). The RSBI was calculated using the ratio f/VT.

Two minutes were given before shifting to the next method, so the patient could adapt to the new parameters.

After the measurements, the patient was extubated. Successful extubation was considered as the capacity of the patient to sustain spontaneous breathing for over $72 \mathrm{~h}$. Failed extubation was considered as the need to re-intubate the patient less than $72 \mathrm{~h}$ after extubation [2, 29] (Fig. 1).

\section{Statistical analysis}

Our sample size was calculated using our previous work [10] with the effect to be detected $=19.14$, standard deviation $=$ 20.71 , alpha error $=5 \%$, and power $=80 \%$, suggesting 19 patients.

To compare the values of RSBI obtained by the three different methods, a two-way ANOVA test followed by the Tukey test was employed; the level of significance was set at $5 \%$. The results were presented as average and standard deviation. 
Table 2. Values of RSBI as Obtained From Tested Methods, According to Mechanical Ventilation Duration

\begin{tabular}{|c|c|c|c|c|c|}
\hline \multicolumn{3}{|c|}{ Up to $72 \mathrm{~h}$ of $\mathrm{MV}(\mathrm{n}=18)$} & \multicolumn{3}{|c|}{ Over 72 h of $M V(n=23)$} \\
\hline RSBI_MIN & RSBI_ATC & RSBI_SP & RSBI_MIN & RSBI_ATC & RSBI_SP \\
\hline $38 \pm 18 \#$ & $46 \pm 24 \#$ & $55 \pm 22 \#$ & $39 \pm 14^{*}$ & $51 \pm 19^{*}$ & $78 \pm 29$ \\
\hline
\end{tabular}

RSBI: rapid shallow breathing index; MIN: obtained with pressure support of $5 \mathrm{~cm} \mathrm{H}_{2} \mathrm{O}$ and PEEP of $5 \mathrm{~cm} \mathrm{H}_{2} \mathrm{O}$; ATC: obtained in the automatic tube compensation mode and PEEP of $5 \mathrm{~cm} \mathrm{H}_{2} \mathrm{O}$ ); SP: obtained with the patient disconnected from mechanical ventilation; NS: without statistical significance. *Intragroup comparison ( RSBI_SP). \#Intergroup comparison ( RSBI_SP over $72 \mathrm{~h}$ ).

To identify the best cutoff point and the best method to obtain RSBI, an ROC curve was constructed for the values of RSBI determined by each method - RSBI_MIN, RSBI_ATC, and RSBI_SP - and the area under this curve as well as the 95\% CI were calculated. The ROC curve provided the ratio between the sensitivity and specificity for each cutoff point of an index. The cutoff point that provided the largest sum of sensitivity and specificity and consequently the best accuracy was considered the best cutoff point [30]. The following parameters were calculated: sensitivity, specificity, positive predictive value, negative predictive value, and accuracy.

The software R-Project 2.15 was used for analysis and data comparison.

\section{Results}

During the study period, 40 subjects met the inclusion criteria. Among them, $16(40 \%)$ and $24(60 \%)$ were female and male, respectively. The participants were aged $58 \pm 15$ years, presented APACHE II score of $24 \pm 7$, and had been intubated for $6 \pm 4$ days. The subjects were grouped according to the period of MV: up to $72 \mathrm{~h}$ of MV, $\mathrm{n}=17$ (42.5\%); over $72 \mathrm{~h}$ of $\mathrm{MV}, \mathrm{n}=$ $23(57.5 \%)$ (Fig. 1). Table 1 lists the mean and standard deviation of the demographic data, separated by group. Table 2 summarizes the results of RSBI evaluation in the group up to $72 \mathrm{~h}$ and over $72 \mathrm{~h}$ of MV using the different methods tested here.

When comparing the values of RSBI_MIN, RSBI_ATC, and RSBI_SP, in group up to $72 \mathrm{~h}$, no significant difference was obtained between RSBI MIN and RSBI SP (38 \pm 18 vs. $46 \pm 24$ vs. $55 \pm 22$ ). In group over $72 \mathrm{~h}$, a significant difference was obtained for comparisons between RSBI_MIN and RSBI_SP $(39 \pm 14$ vs. $78 \pm 29)(\mathrm{P}=0.000)$ and between RSBI ATC and RSBI SP $(51 \pm 19$ vs. $78 \pm 29)(\mathrm{P}=0.001)($ Table 2$)$.

When comparing between groups, RSBI_SP values in the group over $72 \mathrm{~h}$ were higher $(78 \pm 29$ vs. $55 \pm 22)(\mathrm{P}=0.039)$ : RSBI_ATC $(78 \pm 29$ vs. $46 \pm 24)(\mathrm{P}=0.000), \mathrm{RSBI}$ MIN $(78$ \pm 29 vs. $38 \pm 18)(\mathrm{P}=0.000)$.

Grouping the subjects with up to $72 \mathrm{~h}$ and over $72 \mathrm{~h}$ of MV according to the extubation outcome, on group up to 72 h, of the 17 subjects, 14 (82\%) were successfully weaned from MV and only three (18\%) failed extubation. On the MV group, over $72 \mathrm{~h}$, of the 23 patients, $12(52 \%)$ were successfully extubated and 11 (48\%) have failed extubation (Table 3 ).

On group up to $72 \mathrm{~h}$, intragroup comparison between subjects that progressed to successful vs. failed extubation did not reveal differences among the tested methods. However, for group over $72 \mathrm{~h}$, significant differences were obtained in successful group for RSBI_MIN and RSBI_SP (37 \pm 16 vs. 65 $\pm 23)(\mathrm{P}=0.0000)$, and in failed group for RSBI_MIN and RSBI_SP $(41 \pm 10$ vs. $93 \pm 28)(\mathrm{P}=0.0000)$, and between RSBI_ATC and RSBI_SP $(58 \pm 18$ vs. $93 \pm 28)(\mathrm{P}=0.0000)$.

Analysis of the accuracy of the cutoff points of 50, 78, and $105 \mathrm{cycles} / \mathrm{min} / \mathrm{L}$ for the different methods of RSBI determination (RSBI MIN, RSBI ATC, and RSBI SP) showed that RSBI_SP associated with the cutoff point $<\overline{7} 8$ resulted in the best positive and negative predictive values concerning the outcome of extubation (Table 4).

Table 3. RSBI Values Obtained From Tested Methods, According to Results of Mechanical Ventilation Duration and Extubation

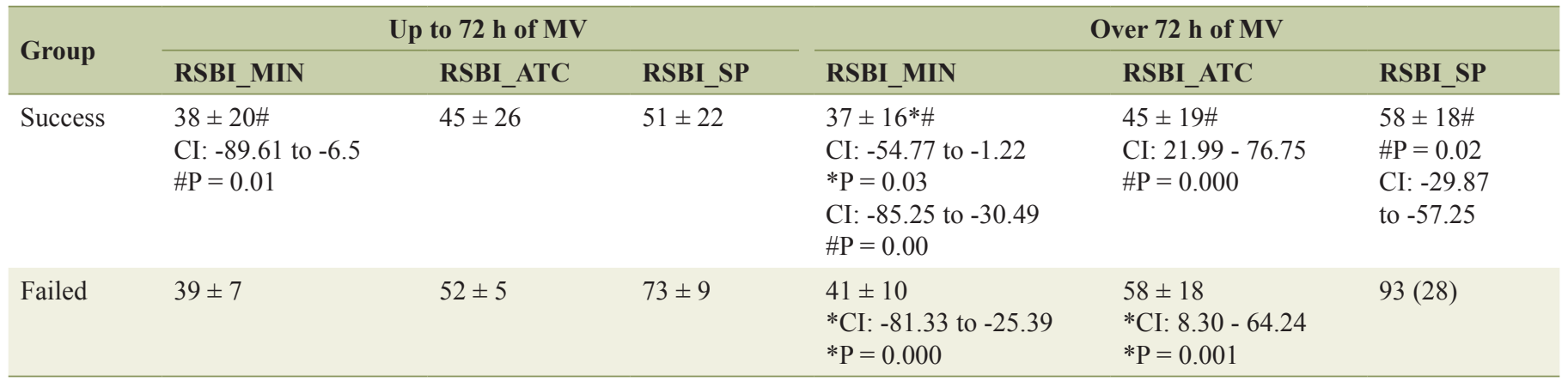

RSBI: rapid shallow breathing index; MIN: obtained with pressure support of $5 \mathrm{~cm} \mathrm{H}_{2} \mathrm{O}$ and PEEP of $5 \mathrm{~cm} \mathrm{H}_{2} \mathrm{O}$; ATC: obtained in the automatic tube compensation mode and PEEP of $5 \mathrm{~cm} \mathrm{H}_{2} \mathrm{O}$; SP: obtained with the patient disconnected from mechanical ventilation; NS: without statistical significance. *Intragroup comparison ( RSBI_SP). \#Intergroup comparison ( RSBI_SP failed). 
Table 4. Accuracy of the RSBI to Predict Successful Extubation With Cutoff Points of 50, 78, and 105 Cycles/Min/L Using Different Methods

\begin{tabular}{lllllll} 
Cutoff & Method & Sensitivity & Specificity & Positive predictive value & Negative predictive value & Accuracy \\
\hline 50 & RSBI_MIN & 0.92 & 0.27 & 0.58 & 0.75 & 0.61 \\
& RSBI_ATC & 0.75 & 0.55 & 0.64 & 0.67 & 0.65 \\
78 & RSBI_SP & 0.33 & 0.91 & 0.80 & 0.56 & 0.61 \\
& RSBI_MIN & 0.92 & 0.00 & 0.50 & 0.75 & 0.48 \\
& RSBI_ATC & 0.92 & 0.27 & 0.58 & 0.73 & 0.61 \\
& RSBI_SP & 0.75 & 0.73 & 0.75 & 1.00 & 0.74 \\
& RSBI_MIN & 1.0 & 0.00 & 0.50 & 1.00 & 0.50 \\
& RSBI_ATC & 1.0 & 0.00 & 0.52 & 0.75 & 0.52 \\
\hline
\end{tabular}

RSBI: rapid shallow breathing index; MIN: obtained with pressure support of $5 \mathrm{~cm} \mathrm{H}_{2} \mathrm{O}$ and PEEP of $5 \mathrm{~cm} \mathrm{H}_{2} \mathrm{O}$; ATC: obtained in the automatic tube compensation mode and PEEP of $5 \mathrm{~cm} \mathrm{H}_{2} \mathrm{O}$; SP: obtained with the patient disconnected from mechanical ventilation.

\section{Discussion}

This study compared how the measurement, cut-off and duration of MV affect RSBI accuracy, demonstrating that the method of obtaining may affect the value of the RSBI for patients over $72 \mathrm{~h} \mathrm{MV}$. However, for the group under MV up to $72 \mathrm{~h}$, the three methods did not differ significantly, in subjects with early MV withdrawal, RSBI_SP, RSBI_MIN, or RSBI_ATC can be used to predict successful extubation. Therefore, for patients of over $72 \mathrm{~h}$ of MV, the values of RSBI obtained by RSBI_SP (traditional method) [9] associated with cutoff point $\leq 78$ cycles $/ \mathrm{min} / \mathrm{L}$ as proposed by Verceles et al [27] were more efficient in identifying patients able to extubation with an accuracy of 0.74 .

One of the greatest challenges faced by professionals working at an ICU is to identify patients that will progress to a failed MV withdrawal, in an attempt to avoid the impacts caused by unsuccessful extubation. The incidence of failed extubation varies from $6 \%$ to $47 \%[3,31,32]$ and differs considerably among the studied populations, being more frequent in populations with higher severity at the moment of admission to the ICU (as defined by the high values of APACHE II score) and longer MV [8, 13].

RSBI has been the most often employed index to evaluate MV withdrawal, even in more severely ill patients. The decision to withdraw MV is not always simple or easy to take. Currently, some institutions rely exclusively on the value of RSBI measured once a day before submitting the patient to SBT or extubation [33].

In this study, we decided to make the RSBI measures after the SBT, because it belongs to a population of highly complex patients according to the high APACHE II scores on admission to the ICU.

Knaus et al [34] stated that the risk of in-hospital death increases exponentially with high APACHE II values, demonstrating that these patients require longer periods of ICU and MV to reach clinical stability.

A longer MV before extubation is related to the difficulty that patients have in maintaining lung volume and expansion.
This difficulty originates from muscle fiber hypotrophy and remodeling, a consequence of inactivity, metabolic disorders like malnutrition, hydroelectrolytic disorders, and use of corticosteroids and neuromuscular blockers that cause polyneuropathy in the critically ill patient [35]. All the aforementioned factors might be associated with the lower values of RSBI_MIN and RSBI ATC in over $72 \mathrm{~h}$, and they culminate in larger patient clinical deterioration. In this scenario, PS and ATC might reduce the respiratory work, compensating for the damaged lung mechanics and the additional load imposed by the endotracheal tube in patients with worse respiratory reserve.

Some papers have compared the RSBI obtained before the SBT, and 30, 60 and 120 min after starting time, and their results showed changes in the RSBI with an increase trend in the group of patients that failed, suggesting a measurement after 30 or 60 min of SBT [36, 37].

Based on this principle, we believe that the order of obtaining the measures could influence the results from different methods, especially when the initial measurement was made using the method proposed by Yang and Tobin [9]. In this method, you must disconnect the subject of MV. Additionally, we have the resistance imposed by the endotracheal tube, which does not happen with other methods where the measurement is performed in the MV with the presence of PEEP and minimum PS values or compensation resistance imposed by endotranquil tube. To minimize this effect, the order of measurements was randomized and a rest of 2 min between measurements was included. This procedure allows the subject to return to the previous MV parameters generating a better stabilization of the RR and minute volume prior to next measurement.

Since the proposal of Yang and Tobin [9], RSBI has been demonstrated to have a reduced predictive ability after 7 days of MV.

By grouping the subjects into individuals who underwent early MV withdrawal (up to $72 \mathrm{~h}$ ) and individuals who had MV withdrawn after over $72 \mathrm{~h}$ and analyzing the tested methods, it was possible to verify lower values of RSBI in up to $72 \mathrm{~h}$, without statistical difference among the tested methods. In over $72 \mathrm{~h}$, RSBI_MIN and RSBI_ATC were significantly lower than RSBI_SP. 
Bien et al [38] evaluated the variability of the respiratory pattern measured during SBT in patients that received PS and PEEP of $5 \mathrm{~cm} \mathrm{H}_{2} \mathrm{O}$ or ATC with $100 \%$ compensation, PEEP of $5 \mathrm{~cm} \mathrm{H}_{2} \mathrm{O}$, and T-tube, and they verified decreased work of breathing. These authors demonstrated that the use of ATC and PS reduced the variability of the respiratory pattern in patients that progressed to failed extubation.

The application of PS and ATC to evaluate RSBI aims to facilitate the measurement of this index. However, the results of the present work showed that the values of RSBI obtained under spontaneous breathing (RSBI_SP) were more accurate in the group under longer MV (over $72 \mathrm{~h}$ ). Other studies had already demonstrated that even minimum values of PS and CPAP can influence the value of RSBI $[11,12,39]$.

Nowadays, ATC constitutes an alternative strategy during the final stages of weaning, mainly as SBT, a fact that justifies our interest in validating the predictive value of RSBI_ATC.

The present study has pioneered RSBI_ATC accuracy evaluation, showing that patients undergoing longer MV have lower average RSBI_ATC as compared to RSBI_SP, measured with the patient disconnected from MV. The data demonstrate loss of the positive predictive value of RSBI_ATC to identify patients that progress to failed extubation. Our results agree with those of Halberthur et al [39], who investigated the outcome of extubation after $2 \mathrm{~h}$ of TRE using PS, ATC, and Ttube, to show that the value of RSBI_ATC measured before extubation was lower as compared to the RSBI_SP.

Another interesting point of the present study was a high number of patients who evolved with extubation failure (35\%) the total sample and (52\%) in the group with MV above $72 \mathrm{~h}$, even after undergoing a successful SBT. In our opinion, it is related to higher APACHE II values and greater severity of the patients in this sample. To evaluate the best cutoff point able to identify failed MV withdrawal in a population undergoing MV for less than $72 \mathrm{~h}$ and over $72 \mathrm{~h}$, three cutoff points were selected: 50,78 , and $105 \mathrm{cycles} / \mathrm{min} / \mathrm{L}$. The choice of the cutoff point of $50 \mathrm{cycles} / \mathrm{min} / \mathrm{L}$ was based on data reported by Frutos-Vivar et al [25], who evaluated a large group of patients with scheduled extubation. The cutoff point of 78 cycles/ $\mathrm{min} / \mathrm{L}$ was chosen because it represented the average values of RSBI in patients that progressed to successful MV removal in a population with prolonged MV [27]. Finally, the pioneering work of Yang and Tobin [9] suggested the cutoff point of 105 cycles/min/L.

The use of the cutoff point of 105 cycles $/ \mathrm{min} / \mathrm{L}$ did not help any of the tested methods to identify failed extubation, as demonstrated by other studies [23, 24, 40]. Some investigations have shown that the average RSBI in patients that progressed to successful extubation was well below this cutoff point. This suggests that specific values should be used for specific populations. In the present investigation, the cutoff point of 78 cycles $/ \mathrm{min} / \mathrm{L}$ associated with the RSBI_SP method (measurement of RSBI without PS) led to the best accuracy associated with a balance between the positive and negative predictive values. This revealed the good ability of the RSBI_SP method to identify successful and failed extubation, in agreement with the paper by Verceles et al [27], who reported an average value of RSBI of $78 \mathrm{cycles} / \mathrm{min} / \mathrm{L}$ in patients that underwent prolonged MV and had successful extubation.
A limitation of this study may have been the expected time between measurements $(2 \mathrm{~min})$. Nevertheless, it reproduces the clinical routine, in which the RSBI in the traditional method is always performed after disconnection from MV after ventilatory support. The sample size on subgroup can be considered another limitation. Patients who evolved to tracheostomy without extubation attempts were excluded. Moreover, even with a small sample size, we demonstrate that in patients with more than $72 \mathrm{~h} \mathrm{MV}$, the method of obtaining the RSBI can influence the outcome of extubation.

\section{Conclusion}

Our results suggest that, in patients undergoing MV for over $72 \mathrm{~h}$, the RSBI obtained with the individual disconnected from MV associated with the cutoff point of $78 \mathrm{cycles} / \mathrm{min} / \mathrm{L}$ is the best strategy to identify patients that are ready for MV withdrawal.

\section{Competing Interests}

The authors declare that they have no competing interests.

\section{Author Contributions}

All authors equally contributed to the design, data acquisition and manuscript preparation.

\section{References}

1. Epstein SK. Decision to extubate. Intensive Care Med. 2002;28(5):535-546.

2. MacIntyre NR, Cook DJ, Ely EW, Jr., Epstein SK, Fink JB, Heffner JE, Hess D, et al. Evidence-based guidelines for weaning and discontinuing ventilatory support: a collective task force facilitated by the American College of Chest Physicians; the American Association for Respiratory Care; and the American College of Critical Care Medicine. Chest. 2001;120(6 Suppl):375S-395S.

3. Epstein SK, Ciubotaru RL, Wong JB. Effect of failed extubation on the outcome of mechanical ventilation. Chest. 1997;112(1):186-192.

4. Esteban A, Ferguson ND, Meade MO, Frutos-Vivar F, Apezteguia C, Brochard L, Raymondos K, et al. Evolution of mechanical ventilation in response to clinical research. Am J Respir Crit Care Med. 2008;177(2):170177.

5. Dasta JF, McLaughlin TP, Mody SH, Piech CT. Daily cost of an intensive care unit day: the contribution of mechanical ventilation. Crit Care Med. 2005;33(6):1266-1271.

6. Esteban A, Alia I, Tobin MJ, Gil A, Gordo F, Vallverdu I, Blanch L, et al. Effect of spontaneous breathing trial duration on outcome of attempts to discontinue mechanical ventilation. Spanish Lung Failure Collaborative Group. 
Am J Respir Crit Care Med. 1999;159(2):512-518.

7. Cohen JD, Shapiro M, Grozovski E, Singer P. Automatic tube compensation-assisted respiratory rate to tidal volume ratio improves the prediction of weaning outcome. Chest. 2002;122(3):980-984.

8. Meade M, Guyatt G, Cook D, Griffith L, Sinuff T, Kergl C, Mancebo J, et al. Predicting success in weaning from mechanical ventilation. Chest. 2001;120(6 Suppl):400S424S.

9. Yang KL, Tobin MJ. A prospective study of indexes predicting the outcome of trials of weaning from mechanical ventilation. N Engl J Med. 1991;324(21):1445-1450.

10. Goncalves EC, Silva EC, Basile Filho A, AuxiliadoraMartins M, Nicolini EA, Gastaldi AC. Low pressure support changes the rapid shallow breathing index (RSBI) in critically ill patients on mechanical ventilation. Rev Bras Fisioter. 2012;16(5):368-374.

11. Desai NR, Myers L, Simeone F. Comparison of 3 different methods used to measure the rapid shallow breathing index. J Crit Care. 2012;27(4):418 e411-416.

12. El-Khatib MF, Zeineldine SM, Jamaleddine GW. Effect of pressure support ventilation and positive end expiratory pressure on the rapid shallow breathing index in intensive care unit patients. Intensive Care Med. 2008;34(3):505510 .

13. Lee KH, Hui KP, Chan TB, Tan WC, Lim TK. Rapid shallow breathing (frequency-tidal volume ratio) did not predict extubation outcome. Chest. 1994;105(2):540-543.

14. Lessa FA, Paes CD, Tonella RM, Araujo S. Comparison of the rapid shallow breathing index (RSBI) calculated under direct and indirect form on the postoperative period of cardiac surgery. Rev Bras Fisioter. 2010;14(6):503509.

15. Patel KN, Ganatra KD, Bates JH, Young MP. Variation in the rapid shallow breathing index associated with common measurement techniques and conditions. Respir Care. 2009;54(11):1462-1466.

16. Santos Lde O, Borges MR, Figueiredo LC, Guedes CA, Vian BS, Kappaz K, Araujo S. [Comparison among three methods to measure the rapid shallow breathing index in patients submitted to weaning from mechanical ventilation]. Rev Bras Ter Intensiva. 2007;19(3):331-336.

17. Fabry B, Guttmann J, Eberhard L, Wolff G. Automatic compensation of endotracheal tube resistance in spontaneously breathing patients. Technol Health Care. 1994;1(4):281-291.

18. Haberthur C, Elsasser S, Eberhard L, Stocker R, Guttmann J. Total versus tube-related additional work of breathing in ventilator-dependent patients. Acta Anaesthesiol Scand. 2000;44(6):749-757.

19. Haberthur C, Fabry B, Stocker R, Ritz R, Guttmann J. Additional inspiratory work of breathing imposed by tracheostomy tubes and non-ideal ventilator properties in critically ill patients. Intensive Care Med. 1999;25(5):514519.

20. Haberthur C, Fabry B, Zappe D, Guttmann J. Effects of mechanical unloading/loading on respiratory loop gain and periodic breathing in man. Respir Physiol. 1998;112(1):23-36.
21. Reissmann H, Auer F, Peters K, Prause A. During pressure support ventilation automatic compensation for endotracheal tube resistance reduces patient work of breathing and improves patient-ventilator synchrony. Intensive Care Med. 1996;22:122.

22. Fabry B, Haberthur C, Zappe D, Guttmann J, Kuhlen $\mathrm{R}$, Stocker R. Breathing pattern and additional work of breathing in spontaneously breathing patients with different ventilatory demands during inspiratory pressure support and automatic tube compensation. Intensive Care Med. 1997;23(5):545-552.

23. Boutou AK, Abatzidou F, Tryfon S, Nakou C, Pitsiou G, Argyropoulou P, Stanopoulos I. Diagnostic accuracy of the rapid shallow breathing index to predict a successful spontaneous breathing trial outcome in mechanically ventilated patients with chronic obstructive pulmonary disease. Heart Lung. 2011;40(2):105-110.

24. Vidotto MC, Sogame LC, Calciolari CC, Nascimento OA, Jardim JR. The prediction of extubation success of postoperative neurosurgical patients using frequency-tidal volume ratios. Neurocrit Care. 2008;9(1):83-89.

25. Frutos-Vivar F, Esteban A, Apezteguia C, Gonzalez M, Arabi Y, Restrepo MI, Gordo F, et al. Outcome of reintubated patients after scheduled extubation. J Crit Care. 2011;26(5):502-509.

26. Capdevila XJ, Perrigault PF, Perey PJ, Roustan JP, d'Athis F. Occlusion pressure and its ratio to maximum inspiratory pressure are useful predictors for successful extubation following T-piece weaning trial. Chest. 1995;108(2):482489.

27. Verceles AC, Diaz-Abad M, Geiger-Brown J, Scharf SM. Testing the prognostic value of the rapid shallow breathing index in predicting successful weaning in patients requiring prolonged mechanical ventilation. Heart Lung. 2012;41(6):546-552.

28. Goldwasser R, Farias A, Freitas EE, Saddy F, Amado V, Okamoto V. [Mechanical ventilation of weaning interruption]. J Bras Pneumol. 2007;33(Suppl 2S):S128-136.

29. Seymour CW, Martinez A, Christie JD, Fuchs BD. The outcome of extubation failure in a community hospital intensive care unit: a cohort study. Crit Care. 2004;8(5):R322-327.

30. Zou KH, O'Malley AJ, Mauri L. Receiver-operating characteristic analysis for evaluating diagnostic tests and predictive models. Circulation. 2007;115(5):654-657.

31. Miller RL, Cole RP. Association between reduced cuff leak volume and postextubation stridor. Chest. 1996;110(4):1035-1040.

32. Esteban A, Frutos F, Tobin MJ, Alia I, Solsona JF, Valverdu I, Fernandez R, et al. A comparison of four methods of weaning patients from mechanical ventilation. Spanish Lung Failure Collaborative Group. N Engl J Med. 1995;332(6):345-350.

33. Ely EW, Baker AM, Evans GW, Haponik EF. The prognostic significance of passing a daily screen of weaning parameters. Intensive Care Med. 1999;25(6):581-587.

34. Knaus WA, Wagner DP, Draper EA, Zimmerman JE, Bergner M, Bastos PG, Sirio CA, et al. The APACHE III prognostic system. Risk prediction of hospital 
mortality for critically ill hospitalized adults. Chest. 1991;100(6):1619-1636.

35. Bien MY, Shui Lin Y, Shih CH, Yang YL, Lin HW, Bai KJ, Wang $\mathrm{JH}$, et al. Comparisons of predictive performance of breathing pattern variability measured during T-piece, automatic tube compensation, and pressure support ventilation for weaning intensive care unit patients from mechanical ventilation. Crit Care Med. 2011;39(10):22532262.

36. Chatila W, Jacob B, Guaglionone D, Manthous CA. The unassisted respiratory rate-tidal volume ratio accurately predicts weaning outcome. Am J Med. 1996;101(1):6167.

37. Kuo PH, Wu HD, Lu BY, Chen MT, Kuo SH, Yang PC. Predictive value of rapid shallow breathing index measured at initiation and termination of a 2-hour spontane- ous breathing trial for weaning outcome in ICU patients. J Formos Med Assoc. 2006;105(5):390-398.

38. Bien MY, Lin YS, Shie HG, Yang YL, Shih CH, Wang $\mathrm{JH}$, Cheng KC. Rapid shallow breathing index and its predictive accuracy measured under five different ventilatory strategies in the same patient group. Chin J Physiol. 2010;53(1):1-10.

39. Haberthur C, Mols G, Elsasser S, Bingisser R, Stocker R, Guttmann J. Extubation after breathing trials with automatic tube compensation, T-tube, or pressure support ventilation. Acta Anaesthesiol Scand. 2002;46(8):973979.

40. Krieger BP, Isber J, Breitenbucher A, Throop G, Ershowsky P. Serial measurements of the rapid-shallowbreathing index as a predictor of weaning outcome in elderly medical patients. Chest. 1997;112(4):1029-1034. 